\title{
Advances in polymer-stabilized Au nano-cluster catalysis : Interplay of theoretical calculations and experiments
}

\author{
Hiroaki Koga a ${ }^{\text {, Kohei Sakata }}{ }^{\text {, }, ~ Y o s h i n o r i ~ A t o ~}{ }^{\text {b }}$, Akihide Hayashi ${ }^{\text {, }}$ Kohei Tada ${ }^{\text {b, }}$ \\ Mitsutaka Okumura a,b,* \\ a Elements Strategy Initiative for Catalysts and Batteries (ESICB) Kyoto University, 1-30 Goryoohara, Kyoto 615-8245, Japan \\ b Department of Chemistry, Graduate School of Science Osaka University, 1-1 Machikaneyama, Toyonaka, Osaka 560-0043, Japan
}

\section{A R T I C L E I N F}

\section{Article history:}

Received 24 April 2016

Accepted 20 May 2016

Published 5 October 2016

\section{Keywords:}

Polymer-stabilized Au nano-cluster

Aerobic oxidation of alcohols

Interplay of theoretical calculations and experiments

Size effect of Au nano-cluster

Role of the polymers

\begin{abstract}
A B S T R A C T
Polymer-stabilized Au nano clusters (NCs) with mean diameters of 2-10 nm exhibit unique catalytic properties. Several studies have shown that the key factors affecting the catalytic activity of polymer-stabilized Au NCs are control of the Au NC size, appropriate selection of polymers and optimization of the reaction conditions. This is because polymer-stabilized Au NCs exhibit a clear size effect in several catalytic reactions, and the catalytic activity differs with the type of polymer used and the reaction conditions. In order to elucidate the reason underlying the catalytic activity of the polymer-stabilized Au NCs, much attention is being devoted to the interplay of theoretical calculations and experiments in catalysis by polymer stabilized Au NCs. The present article mainly summarizes our progress in understanding this interplay in polymer-stabilized Au NC catalysis.
\end{abstract}

(C) 2016, Dalian Institute of Chemical Physics, Chinese Academy of Sciences. Published by Elsevier B.V. All rights reserved.

\section{Introduction}

$\mathrm{Au}$ is a precious metal that retains its metallic state in nature as its spontaneous oxidation is thermodynamically unfavorable. Hence, Au has been regarded as a chemically inert metal. Accordingly, the classical uses of Au were in jewelry, coins, and ornaments, while the industrial use was in thin wires. Colloidal $\mathrm{Au}$ (particle diameter: $\sim 50-100 \mathrm{~nm}$ ) imparts a red color to glass and is hence used in stained glass windows of cathedrals and churches. In 1987, Haruta and co-workers [1,2] reported that $\mathrm{Au}$ nano clusters ( $\mathrm{Au} \mathrm{NCs}$ ) with diameters of $2-5 \mathrm{~nm}$ deposited on certain metal oxides, such as $\mathrm{Fe}_{2} \mathrm{O}_{3}, \mathrm{Co}_{3} \mathrm{O}_{4}$, and $\mathrm{NiO}$, were remarkably active for $\mathrm{CO}$ oxidation at temperatures as low as $200 \mathrm{~K}$. Hutchings [3,4] also showed the catalytic activity of cationic $\mathrm{Au}$ for the hydrochlorination of acetylene. Consequently, Au NC catalysts have attracted considerable attention in the field of catalysis [5].

Rossi et al. [6] demonstrated that small Au clusters showed an intrinsic catalytic activity for aerobic oxidation. In this reaction, bare Au clusters ephemerally generated in solution can act as catalysts for the oxidation of glucose. These results suggested that the small Au clusters confined in some aggregation inhibitors would act as oxidation catalysts. Therefore, colloidal Au would be an ideal model for oxidation reactions. In the case of colloidal $\mathrm{Au}$, the Au NCs are partially stabilized by multipoint weak interactions with organic stabilizers, so that a part of the cluster surface is exposed and can contribute to the catalytic reaction [7]. Tsukuda and coworkers [8,9] reported that $\mathrm{Au}$

\footnotetext{
* Corresponding author. Tel: +81-6-68505404; Fax: +81-6-68505550; E-mail: ok@chem.sci.osaka-u.ac.jp This work was supported by Japan Science and Technology Agency (JST), Advanced Low Carbon Technology Research and Development Program (ALCA) and Core Research for Evolutional Science and Technology (CREST).

DOI: 10.1016/S1872-2067(16)62463-4 | http://www.sciencedirect.com/science/journal/18722067 | Chin. J. Catal., Vol. 37, No. 10, October 2016
} 
NCs stabilized by poly( $N$-vinyl-2-pyrrolidone) (PVP, $\left.\left(\mathrm{C}_{6} \mathrm{H}_{9} \mathrm{ON}\right)_{n}\right)$, abbreviated as Au:PVP, could selectively oxidize $p$-hydroxybenzyl alcohol to the corresponding aldehyde in water. Following this report, Au:PVP systems were systematically investigated in terms of size-controlled synthesis, electronic structure and activity correlation, and applications in organic transformations. Thus, this article mainly summarizes our progress regarding the interplay of theoretical calculations and experiments on the reactions catalyzed by polymer-stabilized $\mathrm{Au}$ NPs.

\section{Preparation of polymer-stabilized Au nanoclusters}

The technique for preparing polymer-stabilized nano-sized metal clusters has been commonly used in the preparation of colloidal nanocluster catalysts. In 1970s, Toshima and coworkers [10] reported the use of fine colloidal dispersions of transition metals as catalysts for the selective hydrogenation of olefins and dienes. The basic concept underlying the preparation of polymer-stabilized nanoclusters is the reduction of metal ions in the presence of an organic polymer. The main role of the polymer is to inhibit the aggregation of neutral metal atoms at the initial stage to give nano sized metal clusters. The polymers on the Au NC prevent aggregation of the Au NCs and facilitate their dispersion in liquid media. PVP, polyvinylalcohol (PVA) and polyallylamine (PAA), as well as their derivatives, are used in the production of Au NCs. Oxygen, nitrogen, or sulfur-containing functional groups are usually introduced into the polymers to allow coordination to the Au NCs. In particular, PVP has been typically used for stabilizing NCs of precious metals such as Pt, Pd, and Rh [7,11-15], and it has been proposed that the oxygen moiety of PVP interacts with the metal clusters [7]. A conventional synthesis of polymer-stabilized $\mathrm{Au}$ NCs, such as Au:PVP, entails rapid reduction of Au(III) ions with a strong reducing agent $\left(\mathrm{NaBH}_{4}\right)$ in the presence of PVP $[16,17]$. Tsukuda and coworkers [17] used a microfluidic reactor to create a homogeneous mixture of $\mathrm{AuCl}_{4}^{-}$and $\mathrm{BH}_{4}{ }^{-}$solutions for the preparation of Au:PVP. The resulting Au:PVP catalysts were characterized by optical spectroscopy, transmission electron microscopy (TEM), etc. TEM observations of Au:PVP prepared by using the microfluidic reactor indicated that both the mean diameter and size distribution of the Au nanoclusters were smaller than those prepared by the conventional method.

To elucidate the size effect of the polymer-stabilized $\mathrm{Au}$ clusters on catalytic activity, a series of polymer-stabilized $\mathrm{Au}$ NCs were prepared by growing the small NCs as seeds. Additional $\mathrm{AuCl}_{4}^{-}$ions were reduced in the presence of Au:PVP $[9,18,19]$. In this process, a weak reducing agent $\left(\mathrm{SO}_{3}{ }^{2-}\right)$ instead of $\mathrm{NaBH}_{4}$ was used for the reduction of $\mathrm{Au}(\mathrm{III})$ present on the $\mathrm{Au}$ cluster surfaces. A series of Au:PVP catalysts, with mean diameters ranging from 1.1 to $9.5 \mathrm{~nm}$, were obtained [9].

\section{Catalytic reactions}

\subsection{Oxidation of alcohols in water}

The Au:PVP catalyst prepared from Au NCs with $1.3 \mathrm{~nm}$ di-

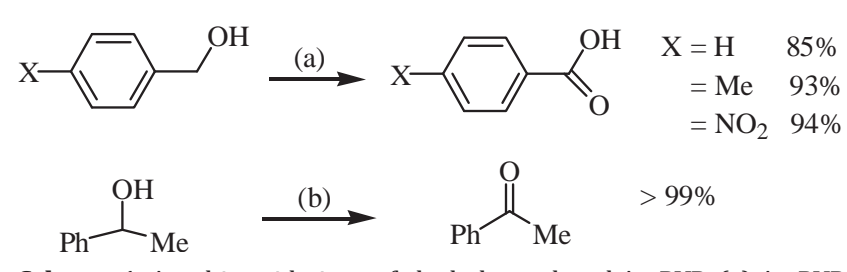

Scheme 1. Aerobic oxidations of alcohols catalyzed Au:PVP. (a) Au:PVP 2 atom\%, $\mathrm{K}_{2} \mathrm{CO}_{3} 300 \mathrm{~mol} \%, \mathrm{H}_{2} \mathrm{O}, 2{ }^{\circ} \mathrm{C}, 24 \mathrm{~h}$; (b) Au:PVP 2 atom\%, $\mathrm{K}_{2} \mathrm{CO}_{3} 300 \mathrm{~mol} \%, \mathrm{H}_{2} \mathrm{O}, 67^{\circ} \mathrm{C}, 24 \mathrm{~h}$.

ameter catalyzed the oxidation of several types of alcohols in water, as shown in Scheme 1. The key feature of these reactions is that they proceed only under aerobic conditions, which means that molecular oxygen dissolved in water acts as the oxidant [18].

Initially, these reactions did not proceed in the absence of a base, in contrast to those in the presence of Pd- or Pt-based catalysts [20-24]. For the first step of the aerobic oxidation of alcohols, the hydrogen elimination from the $\mathrm{OH}$ group of the alcohols must be needed to form the corresponding oxidation reaction products. However, Au NCs show the low catalytic activity for hydrogen elimination from the $\mathrm{OH}$ group of the alcohols adsorbed on Au:PVP. Thus, a base is necessary for the reaction to proceed, i.e., for the production of $\mathrm{RO}^{-}$and $\mathrm{H}^{+}$from $\mathrm{ROH}$ in the liquid phase. A similar trend for behavior of the hydrogen elimination from an allylic alcohol on a Au NC supported catalyst was elucidated theoretically $[25,26]$.

The effects of cluster size on the catalytic activity for the aerobic oxidation of $p$-hydroxybenzyl alcohol have examined (Fig. 1). This reaction is commonly used as a test reaction because the clusters do not aggregate throughout the reaction

(a)
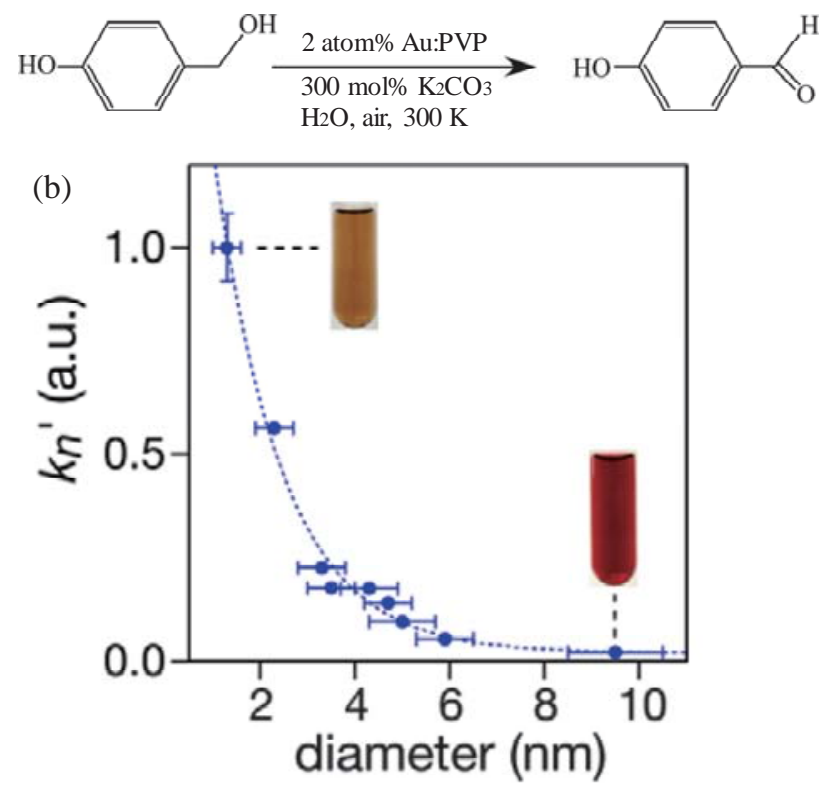

Fig. 1. $p$-Hydroxybenzyl alcohol oxidation catalyzed by Au:PVP. (a) Reaction and its conditions; (b) Rate constant per unit surface area as a function of cluster size, for the oxidation of error bars in the horizontal and longitudinal axes of panel represent standard deviations of the core size and rate constant obtained from three independent batches of samples. Published with permission from Ref. [18]. 
and hydroxybenzaldehyde is selectively obtained. The turnover frequency (TOF) of this reaction was found to appear below 5 $\mathrm{nm}$, and it increased dramatically with a decrease in the size of the Au NCs (Fig. 1) [9,19].

For a rational explanation of the aerobic oxidation of alcohols on polymer-stabilized Au NC catalysts, it is considered that the active molecular oxygen is present on the catalysts. In order to investigate the possibility of activation of molecular oxygen, several experiments were conducted. The results of XPS measurements [19] revealed that the $\mathrm{Au}$ NCs were negatively charged. Theoretical studies also demonstrated that $\mathrm{Au}_{13}$ clusters acquired a negative charge because of electron donation from the carbonyl group of the PVP units to $\mathrm{Au}_{13}$ [27]. The gross negative charge of $\mathrm{Au}_{13}$ increased with an increase in the number of PVP units. $\mathrm{O}_{2}^{-}$is produced on $\mathrm{Au}_{13}$ protected with four PVP units. These results indicated that PVP not only worked as a protecting material to prevent the aggregation of $\mathrm{Au}$ NCs, but also affected the characteristics of the Au NC surface. Further, $\mathrm{O}_{2}$ is activated to form superoxo-like species $\left(\mathrm{O}_{2}{ }^{-}\right)$ on the negatively charged Au clusters protected by PVP to promote the oxidation. The importance of the negatively charged $\mathrm{Au}$ atoms in the clusters are also confirmed by the Ag-doping on the catalytic activity of polymer stabilized $\mathrm{Au}$ clusters in aerobic oxidation of alcohol experimentally [28]. In this case, the doped Ag atom also acts as an electron donor to $\mathrm{Au}$ atoms in the cluster. In addition, it has been reported that the presence of water enhances $\mathrm{O}_{2}$ activation on the negatively charged $\mathrm{Au}_{10}$ cluster [29]. Therefore, water is beneficial for Au:PVP catalysis. Fig. 2 shows a plausible mechanism for alcohol oxidation in the presence of Au:PVP [30]. Theoretical calculations were carried out in order to investigate the mechanism of the aerobic oxidation of the alcohol over polymer-stabilized $\mathrm{Au}$ NC catalysts. The results suggested that the production of $p$-hydroxybenzaldehyde was triggered via both $\mathrm{C}-\mathrm{H}$ bond dissociation of 1-position carbon of $p$-hydroxybenzyl alcohol by the oxygenated $\mathrm{Au} \mathrm{NC}$ and hydride elimination from $p$-hydroxybenzyl alcohol on the Au NC surface. Accordingly, $\mathrm{H}_{2} \mathrm{O}_{2}$ was produced in all the reaction pathways investigated.
Finally, $\mathrm{H}_{2} \mathrm{O}_{2}$ decomposed to afford two $\mathrm{OH}^{-}$ions. Ehara and coworkers [31,32] also showed theoretical investigations for the aerobic oxidation of methanol to formic acid, catalyzed by $\mathrm{Au}_{8}{ }^{-}$and $\mathrm{Au}_{20}$. From these research results, the fundamental mechanism of oxidation was elucidated.

It is well known that the catalytic activities of Au supported catalysts, such as $\mathrm{Au} / \mathrm{TiO}_{2}, \mathrm{Au} / \mathrm{Al}_{2} \mathrm{O}_{3}$, change depending on the support chosen [33]. In the case of the polymer-stabilized $\mathrm{Au}$ NC catalysts, the selection of the polymers is a crucial step. For example, Tsukuda et al. [19] reported that the Au NCs stabilized by poly(allylamine) (PAA; $\left.\left(\mathrm{C}_{3} \mathrm{H}_{5} \mathrm{NH}_{3}\right)_{n}\right)$, abbreviated as $\mathrm{Au}$ :PAA, could also selectively oxidize $p$-hydroxybenzyl alcohol to the corresponding aldehyde under the condition used for Au:PVP; however, its activity is much lower than that of Au:PVP. To elucidate the reason for this difference, Okumura and coworkers [35] investigated the characteristics of these two types of polymer-stabilized $\mathrm{Au}$ NC catalysts using density functional theory (DFT) and molecular dynamics (MD) calculations. From the DFT calculations, it was found that the $\mathrm{O}_{2}$ activation abilities for both Au:PVP and Au:PAA were comparable, while the adsorption energies between the Au NC and the polymers were slightly different. Next, the surface coverage of the Au NC by the stabilizing polymers was investigated by MD calculations. From the trajectories of the MD simulations, the radial occupancy distribution of the polymers in the polymer-stabilized Au NC model systems which was closely related to the cluster surface coverage was calculated based on the van der Waals (vdW) radii of the atoms constituting the model systems [35]. The results are summarized in Fig. 3. It appears that the surface coverage in the vicinity of the Au NC by PAA is larger than that of the Au NC by PVP. From these results, it could be concluded that the difference in the catalytic activities of Au:PVP and Au:PAA is mainly due to the difference in substrate accessibility on the Au NC surface, which in turn is caused by the difference in the $\mathrm{Au} \mathrm{NC}$ surface coverage by the polymers, while $\mathrm{O}_{2}$ activation abilities for both Au:PVP and Au:PAA are almost same. These results suggest that essential roles for the polymer used for the polymer-stabilized Au NCs are the inhibition of Au NCs

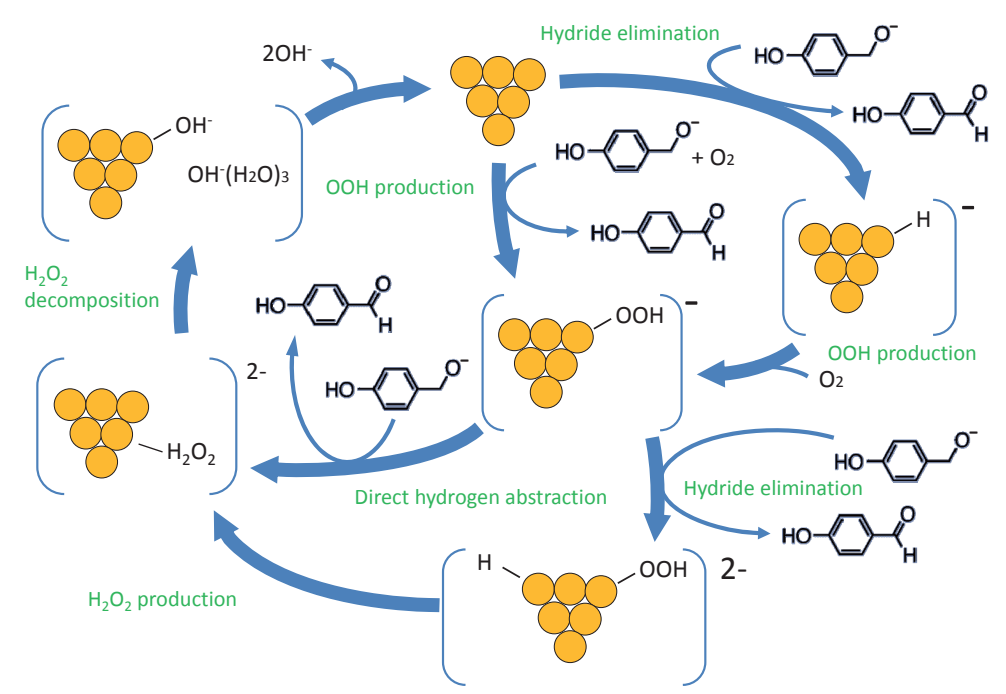

Fig. 2. Plausible reaction pathways for the production of $p$-hydroxybenzaldehyde from $p$-hydroxybenzyl alcohol on the surface of the Au NC catalyst. 

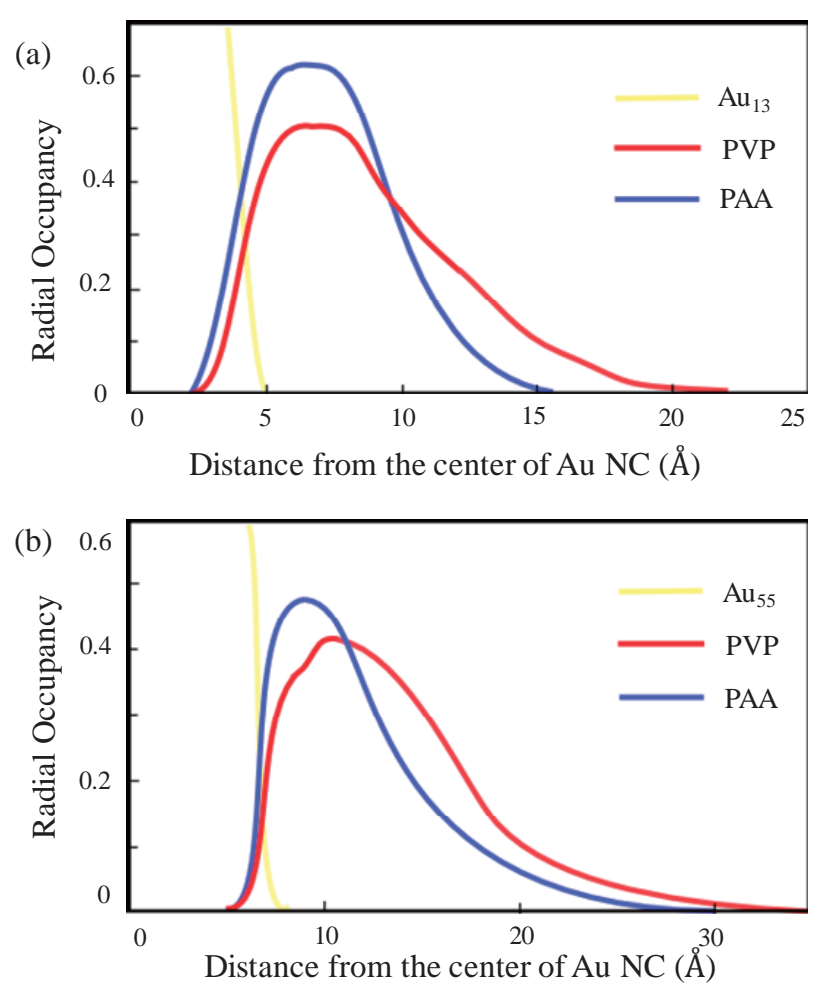

Fig. 3. Average radial occupancy distributions for $\mathrm{Au}_{13}\left(\mathrm{PVP}_{n^{\prime}}\right)_{m}$ and $\mathrm{Au}_{13}\left(\mathrm{PAA}_{n^{\prime}}\right)_{m}(\mathrm{a}), \mathrm{Au}_{55}\left(\mathrm{PVP}_{n}\right)_{m}$ and $\mathrm{Au}_{55}\left(\mathrm{PAA}_{n}\right)_{m}$ (b). The number of adsorbed polymers: $m=1,2,3,4$, polymerization degrees : $n=100 / m$ and $n^{\prime}=36 / m$. Published with permission from Ref. [35].

aggregation, the electron donation to $\mathrm{Au} \mathrm{NCs}$, and less strong passivation of $\mathrm{Au}$ NC surface by the polymer adsorption. Consequently, both the essential nature of the stabilizing polymers and the mechanism of aerobic oxidation of alcohols by polymer stabilized Au NCs were elucidated in detail by both theoretical and experimental investigations.

\subsection{Other reactions}

The polymer stabilized Au NCs in aqueous solution catalyze the oxidation of alcohols into the corresponding acids under basic conditions. This suggests that aldehydes can also be transformed into acids under similar conditions. In particular, the aerobic oxidation of glucose to gluconic acid which is adopted in the pharmaceutical and food industries is an important reaction. There is a strong demand for the use of metal catalysts to achieve large-scale productions of gluconic acid, although biochemical transformations are employed in practice. From this point of view, Au has considerable potential for use as a catalyst because of its high activity for the aerobic oxidation of the alcohols. Haruta and co-workers have developed $\mathrm{Au}$ catalysts on various organic supports, such as cellulose [36] or ion-exchange resins [37], the TOF values of which exceed $32000 \mathrm{~h}^{-1}$.

Toshima and co-workers [38] attempted to tune the catalytic performance of PVP-protected Au NPs by introducing additional metals for the aerobic oxidation of glucose. Generally, $\mathrm{Au}$ exhibits superior catalytic activity than other noble metals such as Pd and Pt. However, Au-Ag (9/1), Au-Pt (8/2) bimetallic, and Au-Pt-Ag (7/2/1) trimetallic NPs showed much higher

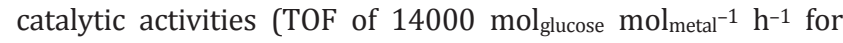
bimetallic [38] and 20000 molglucose $\mathrm{mol}_{\text {metal }}{ }^{-1} \mathrm{~h}^{-1}$ for trimetallic NPs [39], respectively) than monometallic Au NPs (TOF: 4000 molglucose $\operatorname{mol}_{\mathrm{Au}^{-1}} \mathrm{~h}^{-1}$ ), although these NPs had similar mean diameters ranging from 1.4 to $1.6 \mathrm{~nm}$. Toshima and co-workers [40] also prepared Au-Ag bimetallic NPs by physical mixing of colloidal dispersions of $\mathrm{Au}$ and Ag monometallic NPs. In addition, core-shell structured core(Ag)-shell(Au) (2/8) NPs

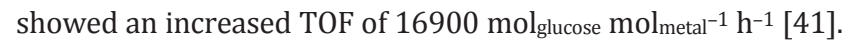
This result was explained by an electron transfer from the $\mathrm{Ag}$ core to the Au shell, which increased the electron density of the $\mathrm{Au}$ shell, making it suitable for $\mathrm{O}_{2}$ activation. DFT calculations performed using an $\mathrm{Ag}_{43} \mathrm{Au}_{12}$ cluster supported the fact that $\mathrm{Au}$ atoms were negatively charged, which was in a good agreement with the XPS results $[42,43]$. Further, Toshima and coworkers [44-46] reduced the amount of Au in inverse Pd core-Au shell bimetallic NPs, and succeeded to obtain crown-jewel clusters, where $\mathrm{Au}$ atoms were located at the top positions of a $\mathrm{Pd}_{147}$ cluster (Fig. 4). This synthetic strategy is based on the difference in the surface free energies of $\mathrm{Au}$ and $\mathrm{Pd}$, and the replacement of $\mathrm{Pd}$ with $\mathrm{Au}$ occurs upon the introduction of $\mathrm{Au}(\mathrm{III})$ ions onto the $\mathrm{Pd}_{147}$ clusters. The obtained crown-jewel clusters showed an extremely high TOF of 195000 molglucose $^{\circ}$ mol $_{\mathrm{Au}^{-1}} \mathrm{~h}^{-1}$, exceeding that of $\mathrm{Au} / \mathrm{ZrO}_{2}$ [44]. This value was much larger than other cluster catalysts. Since the catalytic activity was decreased with an increase in Au loading, it could be presumed that the activities of the $\mathrm{Au}$ atoms positioned at other sites, such as the edge sites, were inferior to that of the top $\mathrm{Au}$ atoms for glucose oxidation [45]. DFT studies using a $\mathrm{Pd}_{43} \mathrm{Au}_{12}$ cluster, in which all the top atoms were replaced with $\mathrm{Au}$, showed that the negative charge density of the top atoms significantly increased as compared to that in the case of a $\mathrm{Pd}_{55}$ cluster, indicating electron transfer from the Pd atoms to the top $\mathrm{Au}$ atoms. The negatively charged top $\mathrm{Au}$ atoms are responsible for the glucose oxidation. DFT results also revealed that the adsorption energy of one $\mathrm{Au}$ atom on the $\mathrm{Pd}(111)$ facet was larger than that on $\mathrm{Pd}(100)$, suggesting that Au was preferentially replaced at the top of the $\operatorname{Pd}(111)$ facets in a $\mathrm{Pd}_{55}$ cluster [46].

The polymer-stabilized $\mathrm{Au}$ and $\mathrm{Au}$ containing NCs catalyze numerous interesting reactions [47-50]. In particular, poly-

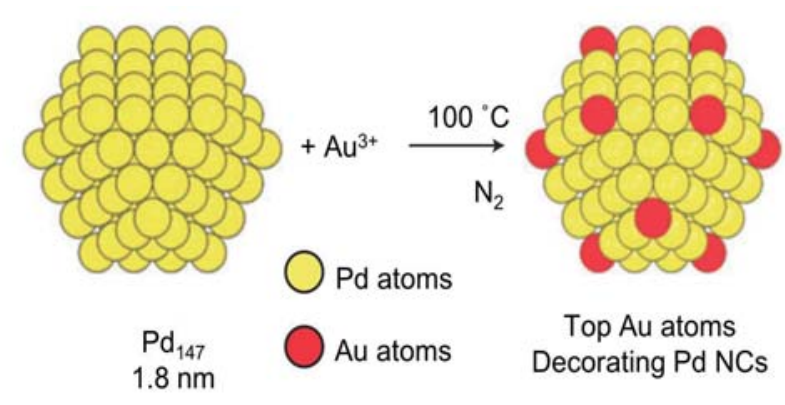

Fig. 4. Schematic illustration of the replacement of top $\mathrm{Pd}$ atoms by $\mathrm{Au}$ atoms, in a Pd mother cluster. Published with permission from Ref. [43]. 
mer-stabilized Au-Pd bimetalic cluster catalysts also play an important role in C-C bond formation reaction. Dhital et al. [51] and Boekfa et al. [52] showed the unique catalytic activity of $\mathrm{Au}-\mathrm{Pd}$ alloy NCs for Ullmann coupling of chloroarenes in aqueous solution at low temperature. The Ullmann coupling product, 4,4'-dimethylbiphenyl, was not obtained when monometallic Au:PVP or Pd:PVP was used as the catalyst. Furthermore, this reaction could not be realized using a physical mixture of monometallic Au and Pd NCs. Consequently, it could be concluded that the Au-Pd bimetalic NC was essential for the generation of Ullman coupling of chloroarenes on the cluster surface. The calculation results also confirmed that the $\mathrm{Au}_{10} \mathrm{Pd}_{10} \mathrm{NC}$ surrounded by four $n$-ethylpyrrolidone molecules could activate the substrate as electron donors and stabilize it.

\section{Conclusions}

We showed that the polymer-stabilized $\mathrm{Au}$ and Au containing NC catalysts exhibited unique catalytic activities in various types of reactions. In each case, the active sites are the surfaces of small Au NC and Au containing NCs. Therefore, it was found that the characteristics of the polymer-stabilized Au NC catalysts were different from those of conventional metal oxide supported Au NC and Au containing NC catalysts. This is mainly due to the result of the electron donation from PVP to the $\mathrm{Au}$ NCs. These results suggested that we could control the reactivity of the polymer-stabilized Au and Au containing NCs by appropriate design of the polymers used. Although there are unsolved problems related to the polymer-stabilized Au NC catalysts, we are convinced that the polymer-stabilized Au NCs would show features different form those of heterogeneous catalysts, owing to the interplay between theoretical and experimental works. In the near future, the interplay between the highly organized model catalysts experiments and the more reliable theoretical calculations is expected to be useful for elucidating the activities and characteristics of the polymer-stabilized Au NC and Au containing NC catalysts.

\section{References}

[1] M. Haruta, T. Kobayashi, H. Sano, N. Yamada, Chem. Lett., 1987, 405-408.

[2] M. Haruta, N. Yamada, T. Kobayashi, S. Iijima, J. Catal., 1989, 115, 301-309.

[3] G. J. Hutchings, J. Catal., 1985, 96, 292-295.

[4] B. Nkosi, J. Coville, G. J. Hutchings, Appl. Catal., 1988, 43, 33-39.

[5] T. Takei, T. Akita, I. Nakamura, T. Fujitani, M. Okumura, K. Okazaki, J. Huang, T. Ishida, M. Hruta, Adv. Catal., 2012, 55, 1-126.

[6] M. Comotti, C. Della Pina, R. Matarrese, M. Rossi, Angew. Chem. Int. Ed. 2004, 43, 5812-5815.

[7] T. Yonezawa, N. Toshima, in: Advanced Functional Molecules and Polymers, H. S. Nalwa Ed., OPA, Amsterdam, 2001, 2, 65-86.

[8] H. Tsunoyama, H. Sakurai, T. Tsukuda, Chem. Phys. Lett., 2006, 429, 528-532.

[9] H. Tsunoyama, N. Ichikuni, H. Sakurai, T. Tsukuda, J. Am. Chem. Soc., 2009, 131, 7086-7093.

[10] N. Toshima, M. Kuriyama, Y. Yamada, H. Hirai, Chem. Lett., 1981, 793-796.
[11] T. Teranishi, M. Hosoe, M. Miyake, Adv. Mater., 1997, 9, 65-67.

[12] T. Teranishi, M. Miyake, Chem. Mater., 1998, 10, 594-600.

[13] N. Toshima, in: Nanoscale Materials, L. M. Liz-Marzän, P. V. Kamat Eds., Kluwer Academic Publishers, Norwell, MA, 2003, 79-96.

[14] R. Narayanan, M. A. El-Sayed, J. Phys. Chem. B, 2005, 109, 12663-12676.

[15] Y. W. Zhang, M. E. Grass, J. N. Kuhn, F. Tao, S. E. Habas, W. Y. Huang, P. D. Yang, G. A. Somorjai, J. Am. Chem. Soc., 2008, 130, 5868-5869.

[16] H. Tsunoyama, H. Sakurai, N. Ichikuni, Y. Negishi, T. Tsukuda, Langmuir, 2004, 20, 11293-11296.

[17] H. Tsunoyama, N. Ichikuni, T. Tsukuda, Langmuir, 2008, 24, 11327-11330.

[18] H. Tsunoyama, H. Sakurai, Y. Negishi, T. Tsukuda, J. Am. Chem. Soc., 2005, 127, $9374-9375$.

[19] H. Tsunoyama, N. Ichikuni, H. Sakurai, T. Tsukuda, J. Am. Chem. Soc., 2009, 131, 7086-7093.

[20] S. S. Stahl, Angew. Chem. Int. Ed., 2004, 43, 3400-3420.

[21] T. Mallat, A. Baiker, Chem. Rev., 2004, 104, 3037-3058.

[22] Y. Uozumi, R. Nakao, Angew. Chem. Int. Ed., 2003, 42, 194-197.

[23] Y. M. A. Yamada, T. Arakawa, H. Hocke, Y. Uozumi, Angew. Chem. Int. Ed., 2007, 46, 704-706.

[24] T. Wang, H. Shou, Y. Kou, H. C. Liu, Green Chem., 2009, 11,562-568.

[25] T. Ishida, J. Aimoto, A. Hamasaki, H. Ohashi, T. Honma, T. Yokoyama, K. Sakata, M. Okumura, M. Tokunaga, Chem. Lett., 2014, 43, 1368-1370.

[26] K. Sakata, H. Koga, T. Ishida, J. Aimoto, M. Tokunaga, M. Okumura, Gold Bull, 2015, 48, 31-37.

[27] M. Okumura, Y. Kitagawa, T. Kawakami, M. Haruta, Chem. Phys. Lett., 2008, 459, 133-136.

[28] N. K. Chaki, H. Tsunoyama, Y. Negishi, H. Sakurai, T. Tsukuda, J. Phys. Chem. C, 2007, 111, 4885-4888.

[29] M. Okumura, M. Haruta, Y. Kitagawa, K. Yamaguchi, Gold Bull., 2007, 40, 40-44.

[30] K. Sakata, K. Tada, S. Yamada, Y. Kitagawa, T. Kawakami, S. Yamanaka, M. Okumura, Mol. Phys., 2014, 112, 385-392.

[31] S. Karanjit, K. Bobuatong, R. Fukuda, M. Ehara, H. Sakurai, Int. J. Quant. Chem., 2013, 113, 428-436.

[32] K. Bobuatong, S Kranjit, R. Fukuda, M. Ehara, H. Sakurai, Phys. Chem. Chem. Phys., 2012, 14, 3103-3111.

[33] M. Okumura, S. Tsubota, M. Haruta, J. Mol. Catal. A, 2003, 199, 73-84.

[34] M. Okumura, S. Nakamura, S. Tsubota, T. Nakamura, M. Azuma, M. Haruta, Catal. Lett., 1998, 51, 53-58.

[35] K. Sakata, Y. Ato, K. Tada, H. koga, S. Yamanaka, T. Kawakami, T. Saito, M. Okumura, Chem. Lett., 2016, 45, 344-346.

[36] D. Widmann, R. J. Behm, Angew. Chem. Int. Ed., 2011, 50, 10241-10245.

[37] M. Farnesi Camellone, P. M. Kowalski, D. Marx, Phys. Rev. B, 2011, 84, 035413/1-035413/18.

[38] H. J. Zhang, N. Toshima, Catal. Sci. Technol., 2013, 3, 268-278.

[39] H. J. Zhang, M. Okumura, N. Toshima, J. Phys. Chem. C, 2011, 115, 14883-14891.

[40] H. J. Zhang, M. Haba, M. Okumura, T. Akita, S. Hashimoto, N. Toshima, Langmuir, 2013, 29, 10330-10339.

[41] H. J. Zhang, J. Okuni, N. Toshima, J. Colloid Interface Sci., 2011, 354, 131-138.

[42] T. Ishida, N. Kinoshita, H. Okatsu, T. Akita, T. Takei, M. Haruta, Angew. Chem. Int. Ed., 2008, 47, 9265-9268.

[43] H. J. Zhang, N. Toshima, K. Takasaki, M. Okumura, J. Alloy Compd., 2014, 586, 462-468.

[44] H. J. Zhang, T. Watanabe, M. Okumura, M. Haruta, N. Toshima, Nat. Mater., 2012, 11, 49-52. 


\title{
Graphical Abstract
}

Chin. J. Catal., 2016, 37: 1588-1593 doi: 10.1016/S1872-2067(16)62463-4

\section{Advances in polymer-stabilized Au nano-cluster catalysis : Interplay of theoretical calculations and experiments}

Hiroaki Koga, Yoshinori Ato, Akihide Hayashi, Kohei Tada, Mitsutaka Okumura*

ESICB Kyoto University, Japan; Osaka University, Japan

Recently, polymer stabilized gold nano clusters have been widely used as quasi-homogeneous catalysts for many reactions. This short review describes recent progress for the elucidation of both its characteristics and the reaction mechanisms.

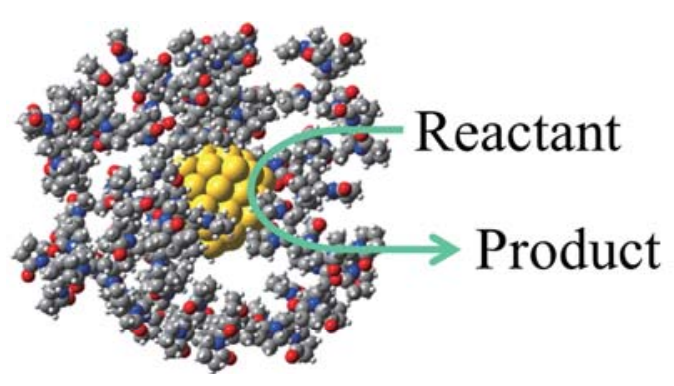

[49] I. Kamiya, H. Tsunoyama, T. Tsukuda, H. Sakurai, Chem. Lett., 2007, 36, 646-647.

[50] H. Sakurai, I. Kamiya, H. Kitahara, H. Tsunoyama, T. Tsukuda, Synlett., 2009, 245-248.

[51] R. N. Dhital, C. Kamonsatikul, E. Somsook, K. Bobuatong, M. Ehara, S. Karanjit, H. Sakurai, J. Am. Chem. Soc., 2012, 134, 20250-20253.

[52] B. Boekfa, E. Pahl, N. Gaston, H. Sakurai, J. Limtrakul, M. Ehara, J. Phys. Chem. C, 2014, 118, 22188-22196.

\section{聚合物稳定的金纳米簇催化：理论计算与实验的相互影响}

\author{
Hiroaki Koga ${ }^{\text {a }}$, Yoshinori Ato ${ }^{\mathrm{b}}$, Akihide Hayashi ${ }^{\mathrm{b}}$, Kohei Tada ${ }^{\mathrm{b}}$, Mitsutaka Okumura ${ }^{\mathrm{a}, \mathrm{b}, *}$ \\ a京都大学催化剂与电池元素战略研究基地, 京都, 日本 \\ ${ }^{\mathrm{b}}$ 大阪大学科学研究院化学系, 大阪, 日本
}

\begin{abstract}
摘要: 平均粒径为 $2-10 \mathrm{~nm}$ 的聚合物稳定的Au纳米簇(NCs)表现出独特的催化性能. 多个研究表明, 影响聚合物稳定的 $\mathrm{Au}$ NCs催化活性的主要因素为: Au NC尺寸的控制、聚合物的选择以及反应条件的优化. 这是由于聚合物稳定的Au NCs在多 个催化反应中表现出明显的尺寸效应, 其催化活性也因所采用的聚合物和反应条件的不同而不同. 为了阐明影响聚合物 稳定的Au NCs催化活性的内在原因, 众多研究者关注于聚合物稳定的Au NCs催化中的理论计算与实验的相互影响. 本文 主要总结了聚合物稳定的Au NCs中这种相互影响的研究进展.
\end{abstract}

关键词: 聚合物稳定的金纳米簇; 醇的有氧氧化; 理论计算和实验的相互影响; 金纳米簇的尺寸效应; 聚合物的作用

收稿日期: 2016-04-24. 接受日期: 2016-05-20. 出版日期: 2016-10-05.

*通讯联系人. 电话: +81-6-6850-5404; 传真: +81-6-6850-5550; 电子信箱: ok@chem.sci.osaka-u.ac.jp

本文的英文电子版由Elsevier出版社在ScienceDirect上出版(http://www.sciencedirect.com/science/journal/18722067). 